\title{
Letters
}

\section{Doctors and managers}

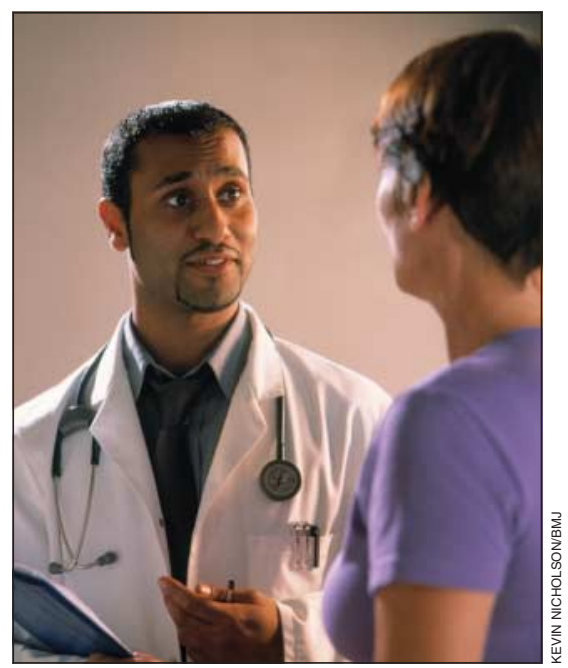

Agreeing objectives could help doctors and managers work well together

EDITOR-Doctors and managers obviously need to work together. To have two powerful groups not working together is likely to frustrate the efforts of both and to damage the service offered to patients. Why then is the relationship between doctors and managers often strained and currently perceived to be at a low ebb? Why is it that two groups, both protesting a desire to put patients at the centre of decision making, often find it difficult to find common ground?

Although doctors and managers apparently agree about the objectives of the NHS, the reality is that the views of the medical profession about its purpose are different from those of managers. This is not surprising given the different backgrounds of doctors and managers.

Doctors are trained in medicine; they tend to be numerate and are trained in the scientific method. They are socialised into a professional model that values both individual and professional autonomy. Many value medicine more highly than they do the NHS. Some perceive themselves as advocates for their patients in the face of governmental and managerial intervention.

Contrast this with managers, who are essentially selected for various characteristics, including good communication skills, ability to create change, and assertiveness, as well as a knowledge and experience of how the NHS functions. Managers have a clear sense of hierarchy and are less concerned with personal or professional autonomy.
They recognise lines of accountability and accept that these extend outside their organisation, ultimately to the secretary of state and to government.

How can these two groups be successfully brought together?

To assume that doctors and managers agree about objectives when they meet may be wrong. In practical terms, therefore, it is often worthwhile making certain that objectives are shared before debating the process. If agreement cannot be reached then there is little point in debating process-the debate needs to be more fundamental. But if agreement can be reached about the objective then the collective creativity of doctors and managers working together can be exciting, worthwhile, and rewarding.

Hugo Mascie-Taylor trust medical director Leeds Teaching Hospital NHS Trust, St James's University Hospital, Leeds LS9 7TF

\section{"You just don't understand"}

EDITOR-Whether this cry is that of a beleaguered health service manager or a consultant who feels that his or her powers have been eroded a little more, the lack of understanding between managers and doctors is manifest. ${ }^{1}$ Why is this so?

The degrees of certainty and agreement in medicine are often perceived to be greater than they are. Although evidence based medicine informs us that treating hypertension is a good thing, that same evidence will remind us that it is impossible for a doctor to discern whether the patient sat in front of them will be the 1 in 500 people to benefit from the antihypertensive drug on offer. By the time patients have pondered the side effects and remembered something that they were told in the pub it is almost a matter of chance whether they will take the drug-and there are many more barriers to prescribing bendrofluazide. ${ }^{2}$ Yet, patients with hypertension would benefit from the input of a manager to support the interaction between patient and healthcare system, without which the system will fail.

We argue that the reason these tensions exist lies in the opposing world views held by both groups: clinicians see their work as an art to be expressed in the unique care afforded to each patient, and as such intrinsically immune to the homogenisation of management. But managers' world view consists of precisely that-the broad thrusts of commissioning, audit, and risk management.
Both are right. There is depth and mystery in much of medicine, but to stop there would be inadequate. Sense is needed to cope, assure, and improve. Managers need to understand that the process of dividing into manageable parts has real dangers-a loss of meaning. Doctors meanwhile need to understand that through such division, their complex art can be more easily understood. World views can be different and still be complementary.

We commend the notion of professional permeability. Let ideas spread by osmosis between the groups by seeking out the other's perspective. What about doctors and managers sharing a community of practice?

No-they wouldn't understand.

Tim Wilson general practitioner

Mill Stream Surgery, Benson, Oxfordshire OX10 6RL

Tim.Wilson@doh.gsi.gov.uk

Kieran Sweeney general practice research facilitator University of Exeter, Exeter EX2 5EQ

1 Degeling P, Kennedy J, Hill M. Mediating the cultural boundaries between medicine, nursing, and management -the central challenge in hospital reform. Health Ser Manage Res 2001:14;36-8.

2 Freeman AC, Sweeney K. Why general practitioners do not implement evidence: qualitative study. $B M J$ 2001:323:1100.

\section{Should we make managers more} accountable to doctors?

EDITOR-General practitioners are in a privileged position to know how the health and social care system as a whole is working. However, many general practitioners think that managers do not pay sufficient attention to their concerns and issues. ${ }^{1}$ They feel marginalised in decision making. This can lead to conflict, "tribalism," and dysfunctional relationships between doctors and managers. Steps should be taken to improve this relationship.

One way to do this is to explore the issue of accountability of managers. Although several degrees of accountability of managers exist in the NHS, virtually none relates to a major stakeholder group-that is, the doctors. Managers impose a huge accountability on doctors for performance and use of resources but no routine mechanism is in place for doctors to hold managers to account.

I believe that this should be changed If doctors sensed that managers also had a degree of accountability to them, then this could transform the relationship. Although managers might view this with suspicion as a "controlling" mechanism, I believe that it could actually improve the relationship and promote trust. It should be done 
constructively and positively, and not become bureaucratic. The elements of accountability would need to be defined in a framework. This would be an instrument that would codify the relationship, expectations, rights, and responsibilities. This, like the doctor-patient relationship, should be based on respect and should be seen as a mutual investment.

The British Department of Health should consider expanding the NHS corporate governance framework to include a formal annual accountability agreement between managers and doctors in trusts. Improving accountability can lead to major improvements in the effectiveness and efficiency of public sector organisation and can deliver radical change. ${ }^{2}$

Mayur Lakhani general practitioner

Highgate Medical Centre, Sileby, Loughborough

LE12 7UD

mklakhani@aol.com

ML is also chairman of communications and publishing at the Royal College of General Practitioners.

1 Regen EL. "Driving seat or back seat?" GPs' views on their involvement in primary care groups and trusts. Report of an evaluation. Birmingham: Health Services Management Centre, University of Birmingham, 2002. (wwwhsmc3 bham.ac.uk/hsmc/

2 Giuliani R. Leadership. London: Little, Brown, 2002.

Problems in Dutch hospitals resemble those in British hospitals

EdITOR-As in the United Kingdom, relationships between doctors and managers in Dutch hospitals are problematic. The divide between management and doctors seems to exist everywhere, independent of health system characteristics.

Dutch hospitals are private not for profit organisations financed through social and private insurance schemes. Specialists restrict their work to one hospital only and are paid through salaries $(35 \%)$ or on a fee for service basis $(65 \%)$. Bringing specialists together in a collective body, the medical staff initiated the integration of specialists in hospitals. Past government policies formalised this integration. ${ }^{1}$ However, the divide has not diminished. The reality is a strategic control battle between hospital management and the medical staff. ${ }^{2}$

Unlike in the United Kingdom, the medical profession itself is responsible for the development of practice guidelines, indicators, and external peer review mechanisms (visitatie). This choice has not lessened the problems either. Our research has led to the following insights.

- Integration among professional activities seems more important to enhance coordination than assigning management responsibilities $^{3}$

- External peer review activities of specialists emphasise managerial rather than clinical problems, thus enforcing the need for managerial solutions on the operational level of clinical care ${ }^{4}$

- Management styles that promote selfregulatory capacities of specialists seem more promising than the concept of physician managers
- The central coordination mechanism should be the management of expertise instead of further industrialisation of the medical working processes to nurture professionalisation in a hospital.

There is no alternative to professional expertise. Hospital managers should acknowledge this and find management styles based on the acceptance of mutual roles and responsibilities. The reasons for the control battle are obvious. However, both specialists and managers should be wise enough to see that the problems in patient care ask for re-engineering of the clinical working processes.

Thomas Plochg research fellow

Kiki Lombarts research fellow

Yolande Witman management consultan

Niek Klazinga professor of social medicine

Department of Social Medicine, Academic Medical Center of the University of Amsterdam, PO Box 22660, 1100 DD Amsterdam, Netherlands

Karen Kruijthof research fellow

Institute of Health Policy and Management,

Erasmus University Rotterdam, PO Box 1738, 3000 DR Rotterdam, Netherlands

1 Commissie Modernisering Curatieve Zorg. Gedeelde Zorg, Betere Zorg. [Committee for the modernisation of Curative Care. Shared care, better care] Zoetermeer: Hageman, 1994 Care. Shared care, better care.] Zoetermeer: Hageman, 1994 Scholten G, van der Grinten TED. Integrating medica specialists and hospitals. The growing relevance of collec tive organisation of medical specialists for

governance. Health Policy 2002;62:131-9. moch I, Klazinga NS, Casparie AF. The medical specialist mosaic: a double integration between the medical

the hospital organisation. Utrecht: VVAA, 1998. Lombarts MJH, Klazinga NS. A policy analysis of the introduction and dissemination of external peer review (visitatie) as a means of professional self-regulation period 1985-2000. Health Policy 2001;58:191-213.

\section{Values and leadership}

\section{Leadership is failing to adhere to values} in the NHS

EDITOR-Pendleton and King are wrong to think that values from the commercial sector could be applicable to the healthcare sector. The basic difference between commercial sector and healthcare sector is that commercial companies value their staff on the basis that they will generate more cash, and reward them in the form of bonuses, higher salaries, or other perks.

The healthcare sector does nothing of the sort. It depends on the caring and conscientious workers to do their best for the patients and derive satisfaction from it. Instinctively, all humans like to be valued and recognised, and if workers are not valued then no amount of leadership would enthuse them into performing at their best. This recognition does not have to be only of a financial nature. In the past it came in the form of considerable autonomy and respect for people's hard work.

Excessive politicisation and managerial control has taken away a lot of staff's professional freedom, and morale is at an all time low. Another problem with the NHS is that most of its leaders have a conflict of interest. The number of medical or clinical directors or doctors in managerial positions who also have a thriving private practice may serve as an example. Most would be considered to have a vested interest in reducing the efficiency and output of the NHS. Such people cannot command respect from their colleagues. Successful leaders lead by example. What sort of example do these leaders set?

I think that every NHS worker knows what values they are supposed to believe in and strive for. It is the leadership that is failing it by not setting the right example.

Pramod P Bapat consultant anaesthetist Arrowe Park Hospital, Upton, Wirral CH49 5PE pbapat@hotmail.com

Competing interests: None declared.

I Pendleton D, King J. Values and leadership. BMJ 2002;325:1352-55. (7 December.)

\section{Chief executives need to participate in} conversation on values and live them

Editor-My consultancy, the Values Partnership, will be working with some NHS organisations on leadership development and change. Pendleton and King articulate well the enormous benefits of aligning an organisation around a shared set of values. In our work with companies we have found that this alignment is the fundamental lever for driving change.

Without it, the only tools are manipulation, force, or domination, explaining the conflict that many organisations currently experience in trying to drive change. Three additional points are drawn from our experience.

Firstly, most NHS employees are personally aligned with the ultimate aims of the organisation, but this commitment seems to be manipulated by management. Basic factors such as trust and relationship are missing.

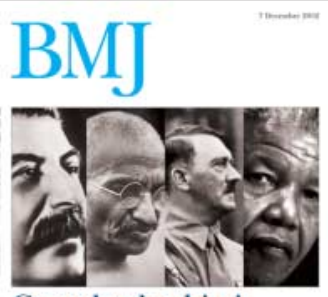

Great leadership is

based on values

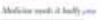

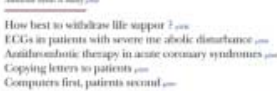

Secondly, the only way management and clinicians are going to find ways to deliver quality care for patients while adhering to budgetary constraints and hitting Whitehall targets is through alignment on higher level values and vision. Everyone is on the same side; problems become shared issues; and collaboration can happen. We have done this with clients many times, and it works.

Thirdly, the chief executive is critical in driving this process. Without a chief executive willing to participate in the conversation on values, to communicate the values, and to live them in his or her daily life, nothing will happen. We have seen many initiatives such as this one fail because management try to "do" values on the rest of the organisation without 
personally getting into the conversation seriously.

This values led approach to change is validated by the results of our clients and no doubt those of the authors, and proved by a lot of management research. ${ }^{2.3}$

Miles D A Protter managing partner

Values Partnership, London NW3 2JY

miles@thevaluespartnership.com

Competing interests: None declared.

1 Pendleton D, King J. Values and leadership. $B M J$ 2002;325:1352-55. (7 December.)

2 Collins J. Good to great. London: Random House, 2000.

3 McCall A, ed. 100 best companies to work for 2002-isn't it

time you found one? Sunday Times 2002 Mar 24. (Supplement.)

\section{Global leadership is in disarray}

EDITOR-The controversy about the BMJ's cover of 7 December may have detracted from the basic issue of the need for charismatic global leadership in health, as mentioned in the article by Pendleton and King. ${ }^{12}$ Hitler and Stalin, despicable as they were, were leaders of their times and had considerable following in their constituencies. That their brand of "leadership" wrought havoc on mankind in general and their subjects in particular is also a fact of history. The point is that nations often have tragedy thrust upon them through the acts of tyrants and bigots. In contrast, the vision and courage of leaders such as Gandhi and Mandela can offer hope and point a way forward in the darkest of times. The above analogy does reflect the way in which many health systems are structured and operate under dictators and despots.

Despite a steady stream of scientific discoveries, as well as progress in genomics and biotechnology, global health is in disarray today. Not only is inequity widespread and increasing, but in many parts of the world HIV, multidrug resistant tuberculosis, and malaria are wiping out an entire generation. Apart from lack of resources in many parts of the world, morally bankrupt, corrupt, and inept leaders (both politicians and bureaucrats) are responsible for many of the health problems. This crisis of leadership is by no means limited to developing countries.

It is also sobering to note that, in the aftermath of 11 September, the world has spent much more on arms and preparing for war than in supporting development and promotion of global health. Today the sick and impoverished of the world need a leadership in promoting global health and development that draws from the vision and courage of Gandhi and Mandela. If it takes a cover to shock us into introspection, so be it.

Zulfiqar Ahmed Bhutta Husein Lalji Dewraj professor of paediatrics and child health

Aga Khan University, PO Box 3500, Stadium Road, Karachi 74800, Pakistan zulfiqar.bhutta@aku.edu

Competing interests: ZAB works with leaders in public health and may be banned from their company as a consequence of this letter.

1 Pendleton D, King J. Values and leadership. BMJ 2002;325:1352-55. (7 December.)

2 Electronic responses. Values and leadership. bmj.com 2002. bmj.com.cgi/eletters/325/7376/1352 (accessed 5 Mar 2003).
The making of a disease: female sexual dysfunction

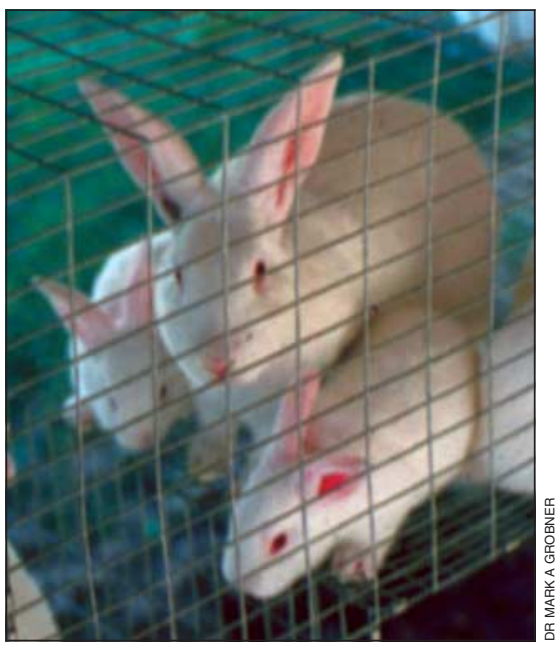

Fluffy bunnies are used as models for "female sexual dysfunction"

\section{Without industry funding little new} research will be possible

EDITOR-Moynihan wrote about female sexual dysfunction as a disease in the making. ${ }^{1}$ As co-chairs for an (unpaid) international committee, commissioned and supported by the American Foundation of Urological Disease, to improve definitions of women's sexual dysfunction, we regret the sensational biased view of industry funded research of biological components of women's sexual function. The common error of equating self reported sexual problems with medically diagnosable disorder is well recognised.

However, to focus only on this and neglect the need for research into aetiology, pathogenesis, and treatment of women's sexual dysfunction from disease, medical, and surgical interventions, is unfortunate. To date, neither the major neurotransmitter involved in vaginal congestion nor the autonomic innervation of the vulval structures has been established. Industry funding facilitates research of interrupted sexual responses from chemotherapy, pelvic surgery, neurological disease, premature menopause, and drug treatment, as well as healthy sexual physiology.

We question the concept of a "new definition of human illness." Women's sexual dysfunction has been diagnosed throughout the centuries. The committee meeting in 1998 tried to modulate definitions in the American Psychiatric Association's Diagnostic and Statistical Manual of Disease, to be more reflective of women's sexuality and dic not create "new disorders." However, the formulation of accurate diagnosis is a continuing process-what is "normal" for women of different ethnic, religious, and cultural backgrounds, and of different ages and life stages is still unclear. Women's sexual function is highly contextual; many aetiological factors-physical, psychological, and interpersonal-must be not only evaluated but included in the diagnosis. Thus the defi- nitions are becoming less rather than more medical. Without accurate definitions of dysfunction, any potential contributory role for pharmacotherapy in holistic management of dysfunction cannot be explored. Without support from the pharmaceutical industry, little new research into sexual physiology is likely or the means by which psychological factors alter the biological processes involved.

Rosemary Basson clinical professor

Department of Psychiatry, University of British

Columbia, BC Centre for Sexual Medicine

Vancouver Hospital, 855 W 12th Avenue,

Vancouver, BC, Canada V5Z 1M9

sexmed@interchange.ubc.ca

Sandra Leiblum professor of psychiatry

Department of Psychiatry, UMDNJ-Robert Wood Johnson Medical School, 675 Hoes Lane

Piscataway, New Jersey, NJ 08854, USA

leiblum@umdnj.edu

Competing interests: Both authors have consulted to various companies, taught at industry sponsored scientific meetings, and received research support

1 Moynihan R. The making of a disease: female sexual dysfunction. BMJ 2003;326:45-7. (4 January.)

\section{Diversity of experiences should be} acknowledged

EDITOR-I have followed the debate on female sexual dysfunction sparked by Moynihan's article with interest. ${ }^{12}$ I agree more attention should be paid to women's sexual concerns. I argue, however, that it is crucial to acknowledge the diverse experiences and viewpoints of women on what constitutes "normal," "healthy" sexuality, and pleasurable sexual intercourse for them-rather than have these matters predetermined by a biomedical and pharmacological model of sexuality.

My colleagues and I conducted an indepth qualitative study, funded by the Health Research Council of New Zealand, on the social impact of sexuopharmaceuticals. We asked women and men about their experiences of sexual difficulties-and men's use of Viagra (sildenafil citrate)-in relationships. Participants' accounts of sexual experiences and pleasures were diverse (this finding itself disputes any generalisation about "normal" female and male sexuality).

Of relevance to this debate were the perspectives of those who enjoyed sexual relationships when erections were absent; contrary to medical assumptions about sexual dysfunctions, they did not subscribe to the view that changes in erections (particularly those associated with ageing) were abnormal or dysfunctional. Importantly, some felt pressured to comply with normative ideas about female and male sexuality by partners, doctors, and sexuopharmaceutical advertising campaigns; and a few commented that it was drug company advertising that prompted them to feel anxious in the first place about their own sexual performances. We should therefore be concerned about creating "new" types of sexual problems and performance anxieties in this way. 
The diversity of experiences and viewpoints in our study challenges any model that would reduce normal or healthy sexuality to certain goals or behaviours, or to basic physiological processes that can be manipulated by chemicals. Sexualities-women's and men's-are more complex and unpredictable than the biomedical model implies; more attention should be given to the impact of social, economic and political factors on sexual desires, pleasures, and behaviours.

Annie Potts Health Research Council research fellow Gender Studies, University of Canterbury, Private Bag 4800, Christchurch, New Zealand annie.potts@Canterbury.ac.nz

Competing interests: None declared.

1 Moynihan R. The making of a disease: female sexual dysfunction. BMJ 2003;326:45-7. (4 January.)

2 Electronic responses. The making of a disease. bmj.com 2003. bmj.com/cgi/eletters/326/7379/45 (accessed 12 Mar 2003).

\section{Conspiracy of silence hinders understanding}

EDITOR-Female sexual dysfunction is a real and distressing problem for millions of women. ${ }^{1}$ It can be a result of surgery, antidepressants, hormone treatments, and the menopause. If a woman overcomes her embarrassment enough to complain she is effectively silenced by the constant response that it is psychological (she is imagining it), it does not happen, and there is no physical explanation for what she is reporting.

Her complaint is met with incomprehension and incredulity. Very little understanding and even less help are available out there-even if her doctor is sympathetic there is nothing to offer. In short, she must put up with it and accept that sexual pleasure is finished for her. She is forced to be just one more participant in the conspiracy of silence.

Pauline Lewis patient

Welwyn, Hertfordshire AL6 0XB

paulineeglewis@uk2.net

Competing interests: None declared.

Moynihan R. The making of a disease: female sexua dysfunction. BMJ 2003;326:45-7. ( 4 January.)

\section{Inaccuracies are not helpful}

EDITOR-Moynihan alleges that the pharmaceutical industry influences independent researchers to create a new medical disorder. ${ }^{1}$ His inaccuracies and false allegations are not informative or helpful to researchers and clinicians or women with sexual dysfunction.

The literature documented the dysfunction well before pharmaceutical companies began investigating treatments. In 1992 the International Classification of Diseases and related health problems described and defined female sexual dysfunction. ${ }^{2}$ The 1994 American Psychiatric Association's Diagnostic and Statistical Manual provided comprehensive definitions of the various types of it."

To say that definitions of female sexual dysfunction are being criticised as mislead- ing and potentially dangerous is disingenuous, based on a few opinions, rather than consensus. In the previous issue Stone et al noted the difficulty in defining health and disease. ${ }^{4}$ This observation is accurate for complex and overlapping conditions such as female sexual function.

Consensus meetings are appropriate to agree on definitions and classifications and refine these with additional epidemiological, psychological, and clinical research. Moynihan fails to note that these meetings included academic researchers, clinicians, and sexologists who treat sexual problems as well as regulatory agency experts. Independent experts who see patients lead the discussions.

We suggest the $B M J$ publishes the 1994 classification and definitions of various types of female sexual dysfunction, and the meetings' revised classification and definitions, for the readership to judge whether "a new medical disorder" has been created.

The BMJ's trivialisation of a distressing dysfunction and its cynicism about an ethical pharmaceutical company's activities and those of the independent experts are unfortunate. Our research efforts often are published and widely commented on. The data can sometimes be controversial but occasionally may lead to advances whereby regulated treatments-pharmacological and other-can be legitimately prescribed.

Declan P Doogan senior vice-president

Sandwich Laboratories and Japan Development, Pfizer Global Research and Development, Sandwich, Kent CT13 9NJ

Declan_Doogan@sandwich.pfizer.com

Competing interests: This letter is a response from Pfizer.

\section{Moynihan R. The making of a disease: female sexua dysfunction. BMJ 2003;326:45-7. ( 4 January.) \\ 2 Cooper JE, ed. Pocket guide to ICD-10 Classification of Men- tal and Behavioural Disorders with Glossary and Diagnostic Criteria for Research DCR-10. Edinburgh: Churchill Living- stone, 1992:208-17. \\ 3 American Psychiatric Association. Diagnostic and Statistical Mamial (quich re DSM-IV) Auc (Chapter: Sexual and gender identity disorders.) \\ Stone J. Wojcik W, Dud ide D, Carson. A Lewis Man J, Wojc W, Durance D, Canson A, Lewis $S$, Mackenzie $\mathrm{L}$, et al. What should we say to patients with to offend." BMJ 2002:325:1449-50. (21-28 December.)}

\section{Summary of responses}

mi com

EDITOR-Within six weeks of publication of Ray Moynihan's article we had received 70 responses, 26 of them overtly critical. ${ }^{12}$ The most strident were from women who thought that the article was denying the existence of female sexual dysfunction, so denying help to thousands of women with real and treatable sexual problems.

"It gets very tiring defending the reality of female sexual dysfunction and the need for research," wrote one. "It is because of physicians and journalists like this one that so many women with FSD [female sexual dysfunction] have been suffering in silence for so long." Another wrote, "Most practitioners are still working under the paradigm that all sexual problems are the result of psychological problems, a faulty relationship, or a careless partner. There are a significant number of women who experience physically based sexual dysfunction, and their needs can only be met by doctors who know how to recognise and treat (or refer) appropriately."

Letters from sexual health specialists echoed these sentiments. Most said they understood the complexity of their patients' needs and rejected a narrow biomedical view of sexual dysfunction. Most also agreed, though, that chronic illnesses such as diabetes, drugs, and surgery, particularly pelvic surgery, can all cause serious sexual problems in women.

They and others complained of our woeful ignorance of women's sexuality, and by extension anything that goes wrong with it. How can we know what is wrong, when we don't know what is right?

Respondents with biomedical backgrounds mentioned ignorance of women's basic anatomy, physiology, and biochemistry. Those with more sociological or psychological perspectives said that we don't know what's "normal" because no one has bothered to ask a representative cohort of women. A consumer advocate from New York asked "Do we want surgeons (urologists, gynaecologists) defining sexual dysfunction? More to the point do we want drug industry funded surgeons defining sexual dysfunction?"

"What passes for knowledge about normal female sexuality is still based on the ideas of clinicians and writers at the end of the 19th to the middle of the 20th centuries," wrote a psychologist from Sheffield. "Victorian and patriarchal ideas continue to inform research and popular opinion." She and others think we should stop counting orgasms and reject historical assumptions about sex (such as heterosexuality and monogamy) if we are to make any meaningful progress.

Some women were happy for their problems to be medicalised (because it meant they were finally taken seriously and treated), but other respondents, usually doctors, saw female sexual dysfunction as the latest in a long line of "diseases," conveniently invented or expanded to fit an emerging treatment. The prevalence of "depression" went up sharply after the advent of antidepressants, the menopause became a disease when HRT arrived, and memory loss associated with ageing became "mild cognitive impairment" to allow treatment with anti-dementia drugs. The result, says one psychiatrist, of "uncritical medical thinking up against a pushy drugs industry."

"Profit driven medical research biases medical care toward treatments and strategies that make money for drug companies-all too often at the expense of women's health and lives" wrote a respondent from the National Women's Health Network in the United States. Another added: "Does this not lead to a simplification and impoverishment of what it means to be human?" One doctor criticised his profession for feebly accepting money and gifts from drug companies (then wringing their 
hands about being manipulated) in the same way that people eat burgers then blame McDonald's for making them fat.

In general though, the issue of industry funding took second place to the more heated debate about the nature of women's sexuality. Only a dozen respondents even mentioned it. Four responses defended the drugs industry, or conceded that since decent research into sexual function was well overdue, industry funding was better than no funding at all. The real villains, said one sexual health specialist from Italy, are not drug companies but national health systems, including his own, that cannot or will not pay for independent research on human sexuality.

Alison Tonks associate editor, BMJ

1 Moynihan R. The making of a disease: female sexual dysfunction. BMJ 2003;326:45-7. (4 January.)

2 Electronic responses. The making of a disease bmicom 2 Electronic responses. The making of a disease. bmj.com Feb 2003).

\section{Author's reply}

EDITOR-The many email responses to and ongoing media coverage of my article on female sexual dysfunction bring a welcome public scrutiny to the role of pharmaceutical companies in shaping public attitudes towards health and illness. While also welcoming the letter from Pfizer's Dr Doogan, I respectfully reject his claims of "inaccuracies and false allegations" and suggest interested parties may like to reread the original article.

Less welcome were secretive though ultimately clumsy corporate attempts to orchestrate a community backlash to the points of view of a range of researchers canvassed in the article. One such attempt was made by a public relations company sending confidential emails to women's groups around the world, including the Canadian Women's Health Network, seeking help to "counter" aspects of the BMJ piece on behalf of an unnamed pharmaceutical company. ${ }^{1}$ Canadian journalists recently discovered that Pfizer was in fact the unnamed client. When questioned about their public relations company's secretive attempts to "counter" the article, a Pfizer spokesperson described the activities as "customary and unremarkable" and part of a plan to "establish appropriate platforms to increase patient awareness and recruit for study subjects."

As Barbara Marshall explains, the point of the article was "not to suggest that women's sexual problems are of no medical interest, or that women's suffering from them is immaterial."' Instead, it was to offer reasons "to be cautious about uncritically embracing a disease-model which, like that for erectile dysfunction before it, is expanding to render an increasing number of difficulties as biomedical dysfunctions."

A recent study of widening disease definitions found $75 \%$ of the adult American population may now have at least one of four medical conditions, with half the population having a high cholesterol concentration. ${ }^{3}$ It may well be time to reread Disease Mongers. ${ }^{4}$

Ray Moynihan journalist

1312 31st Street, NW, Washington, DC 20036, USA raymond.moynihan@verizon.net

1 Moynihan R. Company launches campaign to "counter" BMJ claims. BMJ 2003; 326:120. (18 January.)

2 Marshall BL. Difficulties with dysfunctions. bmj.com 2003. bmj.com/cgi/eletters/326/7379/45\#28584 (accessed 13 Mar 2003).

3 Schwartz L, Woloshin S. Changing disease definitions: implications for disease prevalence. Effective Clin Pract 1999;2:76-85.

4 Payer L. Disease-mongers: how doctors, drug companies and insurers are making you feel sick. Chichester: Wiley, 1992.

\section{Company defends "campaign to 'counter' BMJ claims"}

EDITOR-We disagree with the conclusions of Moynihan in his news item on our company's so called campaign to counter claims made in his education and debate article on female sexual dysfunction. ${ }^{12}$

We are a full service communications company specialising in life science and healthcare communications and manage a wide variety of communications programmes to high ethical standards. These programmes include awareness campaigns to support recruitment of potential participants into clinical trials. These trials are governed by strict ethical and regulatory guidelines and our campaigns are developed and managed in accordance with them.

We agree with the $B M J$ in publishing Moynihan's article, which has been useful in highlighting the wide variety of views held by many women and their physicians on female sexual dysfunction. We note that three weeks after the article was published more than 40 authors with views different from those in the article had sent electronic responses to bmj.com. ${ }^{3}$

In tandem with localised advertising to highlight the opportunity to take part in a placebo controlled clinical trial, our media communications are part of a specific programme to raise awareness of female sexual dysfunction and not, as Moynihan suggests, part of a campaign against the $B M J$. We do not want to discredit any point of view as we are interested in generating media debate from all perspectives. In this case this includes working with women's groups around the world with independent and often varying opinions on the different research initiatives in female sexual dysfunction. We have been in communication with particular groups for some time and not specifically as a result of Moynihan's original article as suggested.

Furthermore, we believe that maintaining confidentiality of both the potential new drug under investigation and the sponsor company is paramount in preserving the integrity of the clinical research so that patient recruitment is unbiased and the results obtained, which are subject to detailed scrutiny and interrogation by the regulatory authorities, are valid and comply with international regulations.

Ultimately, wide debate on this subject can only serve to further the interests of patients-our primary concern.

Richard J Cripps managing director HCC De Facto Group, London EC2M 5PG r.cripps@hccdefacto.com

\section{Moynihan R. Company launches campaign to "counter" BMJ claims. BMJ 2003; 326:120. (18 January.) \\ 2 Moynihan R. The making of a disease: female sexual dysfunction. BMJ 2003;326:45-7. (4 January) \\ 3 Electronic responses. The making of a disease bmj.com Electronic responses. The making of a disease. bmj.com
2003. bmj.com/cgi/eletters/326/7379/45 (accessed 22} Jan 2003).

\section{Spending (slightly) less on health and more on the arts}

\section{Robust research is needed}

EDITOR-Smith raises some important issues about the role of arts in our society and on the relative value we attach to arts and health, as reflected in their budgets. ${ }^{1}$ Perhaps a move to divert some modest funding from the health budget into the arts might prove more popular if some positive health benefit can be shown. But, despite the experiences of Simon Rattle (and any artist who has engaged with poverty and exclusion), the health benefits of the arts are not immediately obvious.

Although we might agree with Brown on bmj.com that the arts have positive effects in a hospital environment, there is a lack of robust evidence of the arts providing such benefits in other areas. ${ }^{2}{ }^{3}$

The potential health benefits of participating in the arts to individual people and to the community have received widespread attention in recent years. The arts have been used as a medium for health promotion and as therapeutic interventions; in the case of the United Kingdom, health action zones and social inclusion partnerships arts projects have been used specifically to tackle social exclusion. As with other healthcare and social interventions, the arts might have an impact on health, but such impacts need to be shown, whether the outcomes are improvements in specific health outcomes or increases in rates of social participation.

Perhaps now that the $B M J$ has put the issue on the agenda, the door will open to supporting research in this area.

Christine M Hamilton director

Centre for Cultural Policy Research, University of Glasgow, Glasgow G12 8QQ

C.Hamilton@arts.gla.ac.uk

Mark Petticrew associate director

MRC Social and Public Health Sciences Unit, University of Glasgow

Competing interests: None declared.

1 Smith R. Spend (slightly) less on health and more on the arts. BMJ 2002;325:1432-3. (21 December.)

arts. BMJ 2002;325:1432-3. (21 December.)
2 Hamilton C, Hinks S, Petticrew M. Arts for health: still Hamilton C, Hinks S, Petticrew M. Arts for health: still
searching for the holy grail? J Epidemiol Community Health (in press).

3 Brown SI. Electronic response to: Spend (slightly) less on health and more on the arts. bmj.com 2002. bmj.com/cgi/ eletters/325/7378/1432\#28349 (accessed 28 Feb 2003). 


\section{Public should decide}

EdITOR-In his editorial Smith advocates spending less on health and more on the arts. ${ }^{1}$ The problem with art is that it is profoundly elitist. Switching money from health to art benefits the upper classes (who probably have medical insurance anyway).

What percentage of the population reads poetry, goes to the opera, enjoys or is touched by contemporary art, or cares who wins the Booker prize? Cultural things that most people identify with tend to be self funding-for example, football, pop music, trashy television soaps, etc.

Perhaps diverting public health money to things that are relevant to most people (such as ailing football clubs, youth sport projects, community centres) would be easier to justify - but it really should be up to the public to decide this.

Philip V Kaye histopathologis

Queen's Medical Centre, Nottingham NG7 2UH

philipkaye@mail.qmcuh-r.trent.nhs.uk

Competing interests: None declared.

1 Smith R. Spend (slightly) less on health and more on the arts. BMJ 2002;325:1432-3. (21 December.)

\section{Healthcare budgets can include money for arts}

EDITOR-To replace rheumatoid tablets with Rattle, state funded bathchairs with free access to Bach-is there anything new in Smith's editorial?'

These are Utopian concepts to an artist, hellish to a fiscal utilitarian. Academics have been quibbling for years about the relative worth of funding the written word at the expense of the high tech laboratory. Families and teachers have been split for generations over whether taking the "arts" or "science" track at A level is likely to lead to a more socially useful career. The debate has raged uselessly for at least 40 years. Whether it is "good" for society to give fiscal encouragement to the arts, the Philistine nature of contemporary political culture means that such a proposal is unlikely to produce any more than a scornful or indifferent media or public response.

Fortunately an alternative exists. Healthcare budgets can-and in many countries do-include money for the arts. This can range from money for arts-inspired healthcare education (through theatre in education or arts information projects) to formal strategies of occupational and artistic therapy, university teaching modules that strive to educate doctors and nurses into more empathetic human beings through the use of art and literature, artistic attempts to brighten hospital environments and reduce the clinical atmosphere, and the longstanding culture of "hospital radio."

All these activities are potentially classifiable as arts, and all are an integral and generally accepted part of NHS life and national health care. We don't need to change anything to divert the arts into the nation's health: they're there already. What we can do is learn more from other countries. Countries such as the United States can teach us about medical humanities. Countries such as Cuba and South Africa can teach us about how health care and the community arts can work together and how low budget health education programmes, relayed through the medium of the arts, can greatly improve the general picture of a country's "health."

Kerry S Kidd postdoctoral Wellcome research fellow Institute for Genetics and Biorisks in Society, University of Nottingham, Nottingham NG7 2RD kerry.kidd@nottingham.ac.uk

Competing interests: KSK is currently working on a grant project for humanities in medicine.

1 Smith R. Spend (slightly) less on health and more on the arts. BMJ 2002;325:1432-3. (21 December.)

\section{Sensory stimulation in dementia}

\section{Cause of behavioural and psychological symptoms of dementia needs to be established first}

EDITOR-Burns et al urge caution in prescribing neuroleptic drugs for agitation in dementia and advance the cause of psychosocial alternatives, citing good evidence in support of bright light and aromatherapy.'

A conceptual problem remains. It is analogous to reflex prescription of neuroleptics (although with less risk of side effects) to attempt standard psychosocial cures before assessing causes of the behaviourwell beyond essential screening for physiological aetiology such as infections or drug interactions. For example, sleep disturbance in nursing homes is commonly caused by staff waking residents up. ${ }^{2}$ It would be ludicrous to start bright light therapy without first assessing the behaviour of night staff.

Most incidents of aggression are not random but occur in personal care. ${ }^{3}$ It would be naive to apply some standard psychosocial therapy without first observing and adjusting how personal care is implemented.

Case specificity extends even to what causes behaviour to become "challenging" and thus labelled behavioural and psychological symptoms of dementia. It is idiosyncratic to the individual carer, staff member, or nursing home. ${ }^{34}$ Not surprisingly, aromatherapy can have mixed effects, depending on the person, staff, or nursing home.

In a recent controlled trial the most common interventions were not named therapies but changing the behaviour and attitudes of carers or staff by using emotional support and case specific education. ${ }^{3}$ Overall, a careful assessment, followed by tailored psychosocial or pharmacological interventions, enabled all patients to be managed in place, took less time, and produced far fewer drug side effects than a control group where drug treatment was the frontline treatment.

Effective alternative drugs or adjuncts to drugs certainly include standard approaches such as aromatherapy, but they are not drugs and cannot be conceptualised as such. Each case needs a diagnostic work up, investigating both physiological and psychosocial causes before any treatment is appliedincluding, we suggest, psychopharmacology. In this framework we agree it is important for clinicians to have evidence based treatment such as aromatherapy and bright light in the toolkit.

Esme Moniz-Cook senior clinical lecturer Division of Psychological and Primary Care Medicine, Postgraduate Medical Institute, University of Hull, Hull York Medical School, Hull HU6 7RX E.D.Moniz-Cook@hull.ac.uk

Michael Bird coordinator of aged mental health NSW Southern Area Health Service, PO Box 1845 , Queanbeyan, NSW 2620, Australia

Competing interests: None declared.

1 Burns A, Byrne J, Ballard C, Holmes C. Sensory stimulation in dementia. BMJ 2002;325:1312-3. (7 December.)

2 Schnelle J, Ouslander J, Simmons S, Alessi C, Gravel M. The night time environment, incontinence care, and The night time environment, incontinence care, and
disruption of sleep in nursing homes. J Am Geriatr Soc

Bird M, Llewellyn-Jones R, Smithers H, Korten A. Psychosocial approaches to challenging behaviour in dementia: controlled trial. Report to the Commonwealth Departnealth and Ageing. Canbenra. CDHA, 2002. 4 Moniz-Cook E, Woods R, Gardiner E. Staff factors associated with perception of behaviour as 'challenging' in Mental Health 2000;4:48-55.

5 Brooker DJR, Snape M, Johnson E, Ward D, Payne M. Single case evaluation of the effects of aromatherapy and massage on disturbed behaviour in severe dementia. $\mathrm{Br}$ Clin Psychol 1997;36:287-96.

\section{Bright light may not illuminate}

EDITOR-In their editorial Burns et al discuss the effects of sensory stimulation of patients with dementia. ${ }^{1}$

Trying bright light as an adjunct to sensitive management of behavioural disturbance led to us purchasing a bright light. The first subject threw it to the ground, and so our second unit is screwed to the wall. There we can't get anyone to sit next to it.

We wonder how we will get on with aromatic oils.

Jed Rowe consultant geriatrician

Moseley Hall Hospital, Birmingham B13 8JL jedrowe@geriatrickery.freeserve.co.uk

Competing interests: None declared.

1 Burns A, Byrne J, Ballard C, Holmes C. Sensory stimulation in dementia. BMJ 2002;325:1312-3. (7 December.)

\section{bmj.com}

Letters appearing here are an edited selection of rapid responses originally posted on bmi.com

We ask for all letters to the editor to be submitted as rapid responses via bmj.com

For advice see: bmj.com/rapidresponses 